\title{
Teaching numeracy
}

\author{
Sue Buckley
}

Understanding number concepts and basic mathematical skills is important for many everyday activities in modern societies. Little is understood about the numeracy abilities of people with Down syndrome. At present, it appears that numeracy is an area of relative difficulty and that progress with more complex mathematical understanding is slow. However, some teaching approaches that seek to utilise certain relative strengths to communicate number concepts seem to be useful in practice. Further research is needed to define the precise difficulties experienced by children with Down syndrome and to evaluate teaching strategies.

One definition of numeracy is 'to use mathematics effectively to meet the general demands of life at home, in paid work, and for participation in community and civic life ${ }^{\text {,[1] }}$. Few would argue with the view that a basic understanding of numeracy will enhance all aspects of the quality of life and independence of young people with Down syndrome.

Basic numeracy could be defined as being able to count and to calculate with numbers to 100 . Most countries have decimal systems for money, measuring and weighing, therefore, knowing numbers to 100 would allow individuals to have a working understanding of these systems. Adding and subtracting are the most useful operations to understand. When learning to multiply, some relationships may be more useful than others - for example knowing how to count in tens, fives and twos would enable a young person to be competent with the UK money system, which has coins in these values. (To stress the point, learning to count in threes or sevens would be less useful). Counting in fives will also be relevant for telling the time.

\section{Inadequate research}

There has been very little published information on the numeracy abilities and achievements of individuals with Down syndrome, but the papers that have been published indicate that most teenagers and adults do not reach this level of basic competency ${ }^{[2-4]}$. In a survey of the skills of 46 teenagers with Down syndrome in the $\mathrm{UK}^{[5-7]}$ the teenagers who had been educated in inclusive classrooms had better numeracy skills than those educated in special education classrooms, but even

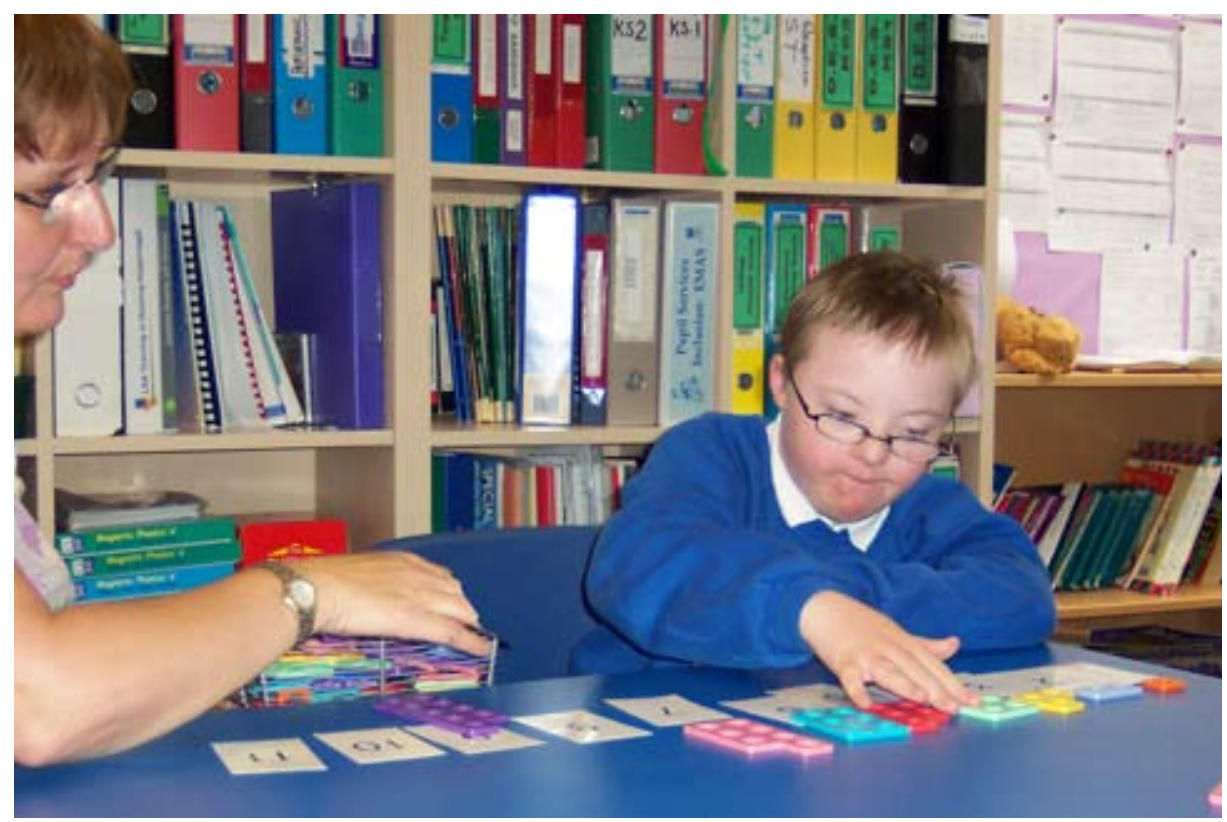

"Numeracy is difficult - and more difficult than literacy - for most children with Down syndrome but we do not know why."

so, very few understood place value (tens and units) and very few could multiply or divide numbers up to twenty.

There is considerable variability in the individual rates of progress reported, with some young people with Down syndrome enjoying maths and doing quite well but most struggling (for a review and case examples see REF 8). One interesting fact is that the numeracy achievements of children with Down syndrome are typically at a lower level than their literacy achievements even when they are receiving good instruction in inclusive classrooms. In a recent longitudinal UK study of 24 pupils (ages 6-14 years) with Down syndrome their number skills were, on average, two years behind their literacy skills ${ }^{[8-10]}$.

At present, therefore, we know that numeracy is difficult - and more difficult than literacy - for most children with Down syndrome but we do not know why. There have been very few studies which have attempted to find out what the stumbling blocks are. One recent UK longitudinal study compared the progress of children with Down syndrome and typically developing children, matched for non-verbal mental age, as they learned to count ${ }^{[11,12]}$. To learn to count, children first have to learn the 'number words' or 'count sequence', that is, to recite correctly the numbers one to twenty. This task requires good short-term memory skills - the words must be learned and always kept in the correct order, before the child can use them to 'count' objects. Children then learn to count small numbers of objects and as they become proficient at this, they begin to understand 


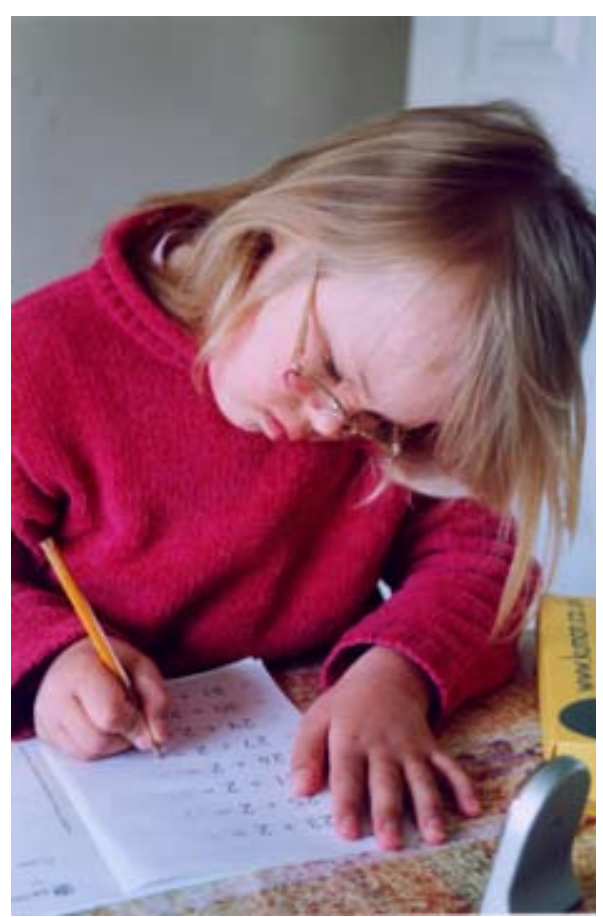

"One possibility for difficulties in progress with mathematics is that the number concepts become more difficult - a child does not need to know that 6 is twice as big as three to count six items correctly. In addition, language becomes important and the child needs to understand concepts such as 'bigger than' and 'the same as'."

that we count to find out 'how many' we have. Once they know that the last count word they use tells them 'how many' they have, they have achieved what is called cardinality ${ }^{[13]}$. They are now beginning to understand that numbers represent quantity. In the longitudinal study, the children with Down syndrome had learned a smaller section of the 'count sequence' than the typically developing children but they could accurately count the same set sizes and understand cardinality as well as the comparison group. (All beginning counters know more words in the count sequence that they can use accurately when counting; e.g. they may be able to correctly recite numbers to 14 but only count sets up to 9 items correctly).

\section{Specific difficulties}

This UK study is encouraging because at this point the children with Down syndrome are doing well. Why, then, does research suggest that they do not continue to learn number skills at a mental-age appropriate rate?

One possibility is that the number concepts become more difficult - a child does not need to know that 6 is twice as big as three to count six items correctly - or indeed that 9 is bigger than 5 . However, to progress in learning to calculate, a child does need to know the relative sizes of number and the relationships between them and this may not become apparent just from practice at counting.

In addition, language becomes important and the child needs to understand concepts such as 'bigger than', 'smaller than', 'more than', 'less than', 'the same as'.

Thirdly, verbal working memory becomes important for learning longer number sequences and multiplication tables, for example, and for doing mental arithmetic. Many research studies report the specific speech, language and working memory delays (relative to non-verbal mental age) that are usually associated with Down syndrome $e^{[14,15]}$.

\section{Teaching practice}

At present, then, the best guides that we have to adaptations that might make learning about number easier for children with Down syndrome will take account of their known language and memory delays. This means being aware that number concepts - even simple ones such as 'more than' - may need to be taught. It means that methods which provide support for working memory and allow the child to work out number problems using tangible materials for each step may help to reduce memory demands. The usual adaptations for children who learn more slowly such as breaking tasks into smaller steps and giving the child the opportunity for more practice should also help.

There is some evidence from a recent group study that children with Down syndrome learn early counting and cardinality skills more quickly when taught using computer software than when spending the same amount of time on similar pencil and paper tasks ${ }^{[16]}$. This could be interpreted as using a method which makes full use of visual supports and plays to the children's strengths. Computer programmes are under the child's control so that they can operate them at the speed they wish - the computer may be more patient than a person and give the child enough time to process the information and respond. In addition, the child is not required to speak the answer. The child uses the mouse to make a response, which may be easier for many children with Down syndrome than using a pencil.

\section{Tactile and visual strategies}

In addition, systems which can visually illustrate the relationships between numbers and help children really understand the value of whole numbers should be beneficial. Several papers in this issue $^{[17-20]}$ describe experience of using number teaching systems which offer some or all of the adaptive strategies that we may predict will help children with Down syndrome. However, at present, we have only a small amount of hard data beyond case studies to provide evidence that they do actually help.

Studies designed to evaluate the effectiveness of different approaches to teaching number to children with Down syndrome, as well as studies which may increase our understanding of why they find number difficult should be a priority for research funding. Meanwhile, parents and teachers need to know what methods may help their children. Numicon,

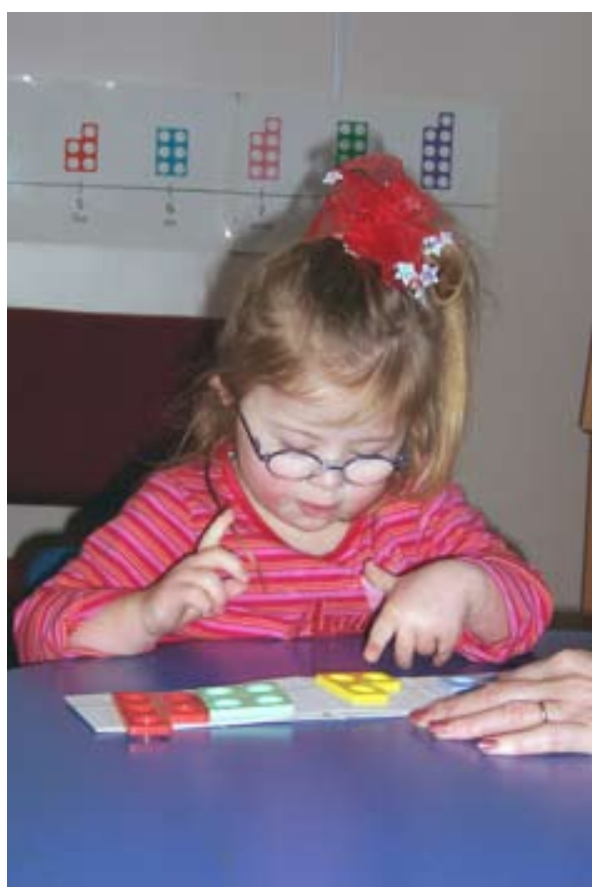
"Systems which can visually
illustrate the relationships
between numbers and help children really understand the value of whole numbers should be beneficial." 
Kumon and Stern methods and materials are three widely promoted approaches. Therefore we invited articles from developers $^{[19]}$, trainers ${ }^{[18]}$ and users ${ }^{[17,20]}$ of these approaches to provide information on each approach allow some comparisons of them.

\section{Kumon}

The Kumon method of teaching numeracy provides the child with daily repetitive paper and pencil practice of small learning steps in order to try to ensure success. This worked for Sam and he achieved a grade in the UK national standard school assessment in mathematics at 16 years old $^{[17]}$. Interestingly, Sam's mother, who is also a primary school teacher, comments that Sam benefited from the rote learning approach - he could use numbers by learning through this method - and suggests he may have actually benefited from not manipulating concrete materials as he learned. 'Sam was neither distracted nor confused by trying to extrapolate abstract from concrete'. This observation warrants further research as, if this is generally true, it would lead to significantly adapting current numeracy teaching approaches for children with Down syndrome. Much more time could be spent on rote learning and less on learning through experience. However, it should be noted that Kumon is not used in schools - it is an extra programme which parents enrol their children in outside school time and any child using the Kumon materials will also be experiencing other approaches to maths in school classrooms.

\section{Stern and Numicon}

The Stern and Numicon methods for teaching number have some benefits in common - both sets of materials help children to gain meaningful concepts for whole numbers and to understand the relative sizes of numbers - and draw on similar original ideas. The materials actually represent the relative sizes of numbers and give children concrete materials to work with to understand counting and calculating operations. The introduction to the Stern article ${ }^{[18]}$ emphasises that the "materials were designed to enable children to learn from their own discovery and thus gain insights into the number system". This is the opposite approach to the rote learning one of Kumon - it advocates using materials to illustrate

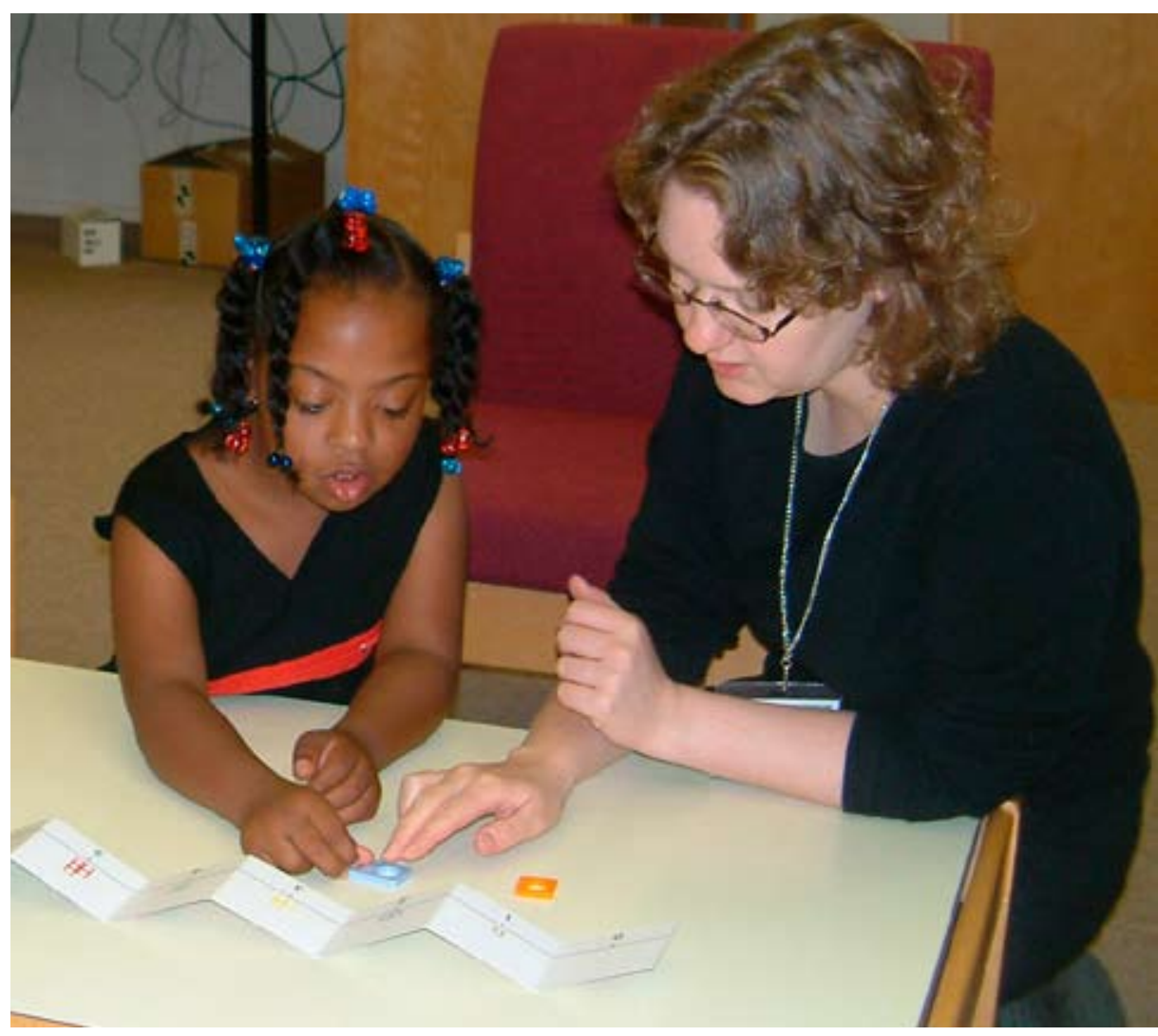

"To progress in learning to calculate, a child needs to know the relative sizes of numbers and the relationships between them and this may not become apparent just from practice at counting."

number concepts. In describing the way in which children learn with the Stern materials, Vikki Horner emphasises that they address a number of the areas of difficulty that may be holding children with Down syndrome back - the materials provide visual illustration of numbers, they reduce memory load and can be used to teach language concepts. She gives clear illustrations of how children's understanding can be taken forward in many different ways with the materials and the Stern programme of activities.

The Numicon materials represent whole numbers in the same pattern shapes as the Stern materials but, in many ways, the similarities in approach and materials end there ${ }^{[19]}$. The Numicon designers have used the shapes to teach children to understand number in a variety of ways that are different from the Stern approach. Readers will be able to see the differences in the detail presented in the two articles. The Numicon patterns can be fitted together in a way that the Stern wooden version of the patterns cannot. The boxes and other materials in the Stern materials provide a number of ways of teach- ing that are not directly provided by the Numicon materials, and vice versa. The Numicon designers have brought their recent experience as maths teachers and a current understanding of how children learn maths to their development of the Numicon step-by-step activities which can be started as early as 18 months.

\section{Evaluation}

It is clear that much thought has gone into both Stern and Numicon approaches and that both offer many fun ways to help any child learn about the world of numbers. The use of the Numicon approach for children with Down syndrome has begun to be evaluated in comparative group studies and these indicate a modest benefit for Numicon when compared with typical UK numeracy teaching in schools. The Stern approach has only recently been introduced in the UK and case reports describe its value but group studies are not yet available. Additional guidance is available on the use of Numicon with children with Down syndrome ${ }^{[21]}$. The Numicon approach is being used in many other countries worldwide and has been translated into other languages. 


\section{Exceptional progress}

The fourth article on numeracy ${ }^{[20]}$, which describes the excellent progress of Katrina, aged ten years really stresses that the three methods described all have their strengths and can be successfully used together. Katrina has used them all. One method may work better for one stage or step of learning, and another at another stage. Katrina is doing exceptionally well

1. Australian Association of Mathematics Teachers. Numeracy $=$ Everyone's Business. The report of the Numeracy Education Strategy Development Conference. Commonwealth of Australia, Canberra. 1997.

2. Bochner S, Outhred L, Pieterse M, Bashash L. Numeracy and money management skills in young adults with Down syndrome. In: Cuskelly M, Jobling A, Buckley S, editors, Down Syndrome Across the Lifespan. London: Whurr. 2002; p.93106.

3. Carr J. Intellectual and daily living skills of 30-year-olds with Down's syndrome: Continuation of a longitudinal study. Journal of Applied Research in Intellectual Disabilities. 2000;13:1-16.

4. Shepperdson B. Attainments in reading and number of teenagers and young adults with Down's syndrome. Down's Syndrome: Research and Practice.1994; 2:97-101.

5. Bird G, Buckley S. Number skills development for teenagers with Down syndrome (11-16 years). Portsmouth, UK: The Down Syndrome Educational Trust. 2002.

6. Buckley S, Bird G, Sacks B, Archer, T. A comparison of mainstream and special school education for teenagers with Down syndrome: Effects on social and academic development. Down Syndrome News and Update. 2002;2:46-54 .

7. Buckley S, Bird G, Sacks B, Archer, T. The achievements of teenagers with Down syndrome. Down Syndrome News and Update. 2002;2:90-96.

8. Bird G, Buckley S. Number Skills for Individuals with Down Syndrome - An Overview. Portsmouth, UK: The Down Syndrome Educational Trust. 2001.

9. Byrne A. The development of reading skills in children with Down syndrome. PhD Thesis. University of Portsmouth. 2001. at maths for her age but her parents make very clear that this level of competence has required many hours of learning and practice to consolidate her understanding and let her move to the next stage. There are some difficult messages here as all the case studies suggest that the children will not reach their potential without additional work and practice outside the school day. This highlights the need for

10. Byrne A, MacDonald J, Buckley SJ. Reading, language and memory skills: A comparative longitudinal study of children with Down syndrome and their mainstream peers. British Journal of Educational Psychology. 2002;72:513-529.

11. Nye J. Numerical Development in children with Down syndrome: the role of parent child interaction: PhD Thesis. University of Portsmouth. 2003.

12. Nye J, Fluck M, Buckley S. Counting and cardinality in children with Down syndrome. Presented at the 'Cognitive Development in Children with Down Syndrome' Symposium, British Psychological Society Annual Conference, 26-19 March, Brighton, UK. 1998.

13. Frye D, Braisby N, Lowe J, Maroudas C, Nicholls $J$. Young children's understanding of counting and cardinality. Child Development. 1989; 60: 1158-1171.

14. Chapman RS, Hesketh LJ. Behavioural phenotype of individuals with Down syndrome. Mental Retardation and Developmental Disabilities Research Reviews. 2000;6:84-95.

15. Freeman SFN, Hodapp RM. Educating children with Down syndrome: Linking behavioral characteristics to promising intervention strategies. Down Syndrome Quarterly. 2000;5:1-9.

16. Ortega-Tudela JM, Gomez-Ariza J. Computer assisted teaching and mathematical learning in Down syndrome children. Journal of Computer Assisted Learning. 2006;22:298-307.

17. Haslam L. Sam's progress with learning mathematics. Down Syndrome Research and Practice. 2007;12(1):32-33.

18. Horner V. Teaching number skills and concepts with Stern Structural Arithmetic materials. Down Syndrome Research and Practice. 2007;12(1):27-31. teachers and families to work together in planning work for children and the need for materials and schemes which make learning at home fun and relatively easy for both children and families.

Sue Buckley is at The Down Syndrome Educational Trust, Portsmouth, Hampshire, UK. e-mail: sue.buckley@downsed.org

doi:10.3104/updates.2031

19. Wing T, Tacon R. Teaching number skills and concepts with Numicon materials. Down Syndrome Research and Practice. 2007;12(1):22-26.

20. McConnochie J, Sneath G. Down Syndrome Research and Practice. 2007;12(1):34-37.

21. Nye J. Teaching number skills to children with Down syndrome using the Numicon Foundation Kit. Portsmouth: The Down Syndrome Educational Trust. 2006.

\section{Stern Structural Arithmetic}

A programme for learning number concepts that is based on reasoning and insight into mathematical relationships, rather than rote learning and counting.

\section{Kumon}

A teaching programme that emphasises a step-by-step approach, building on success and learning through practice.

\section{Numicon}

A multi-sensory approach to arithmetic teaching that uses patterns that are structured to encourage the understanding of number and number relationships.

\section{Teaching number skills to children with Down syndrome using the Numicon Foundation Kit}

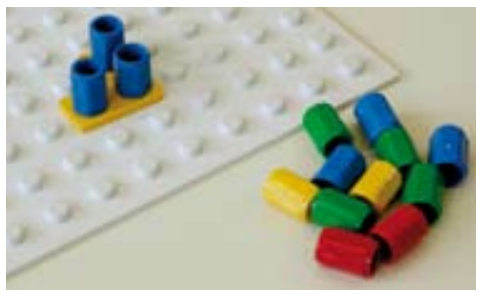

This new book provides practical guidance on how to adapt the Numicon system for children with Down syndrome. With colour photographs and illustrations, the book offers teachers, teaching assistants and families clear and accessible information about how to effectively support learning of number and maths concepts. down syndrome

resources $\&$ activities

Teaching number skills to children with Down syndrome using the Numicon Foundation Kit Joanna Nye

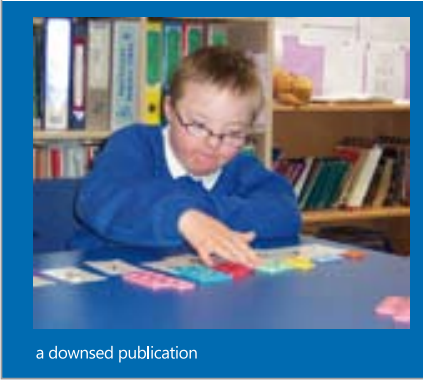

